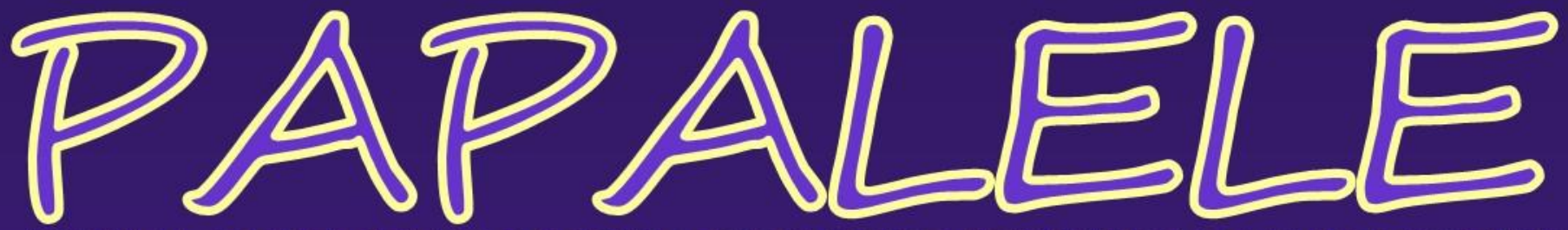
JURNAL PENELITIAN SOSIAL EKONOMI PERIKANAN DAN KELAUTAN

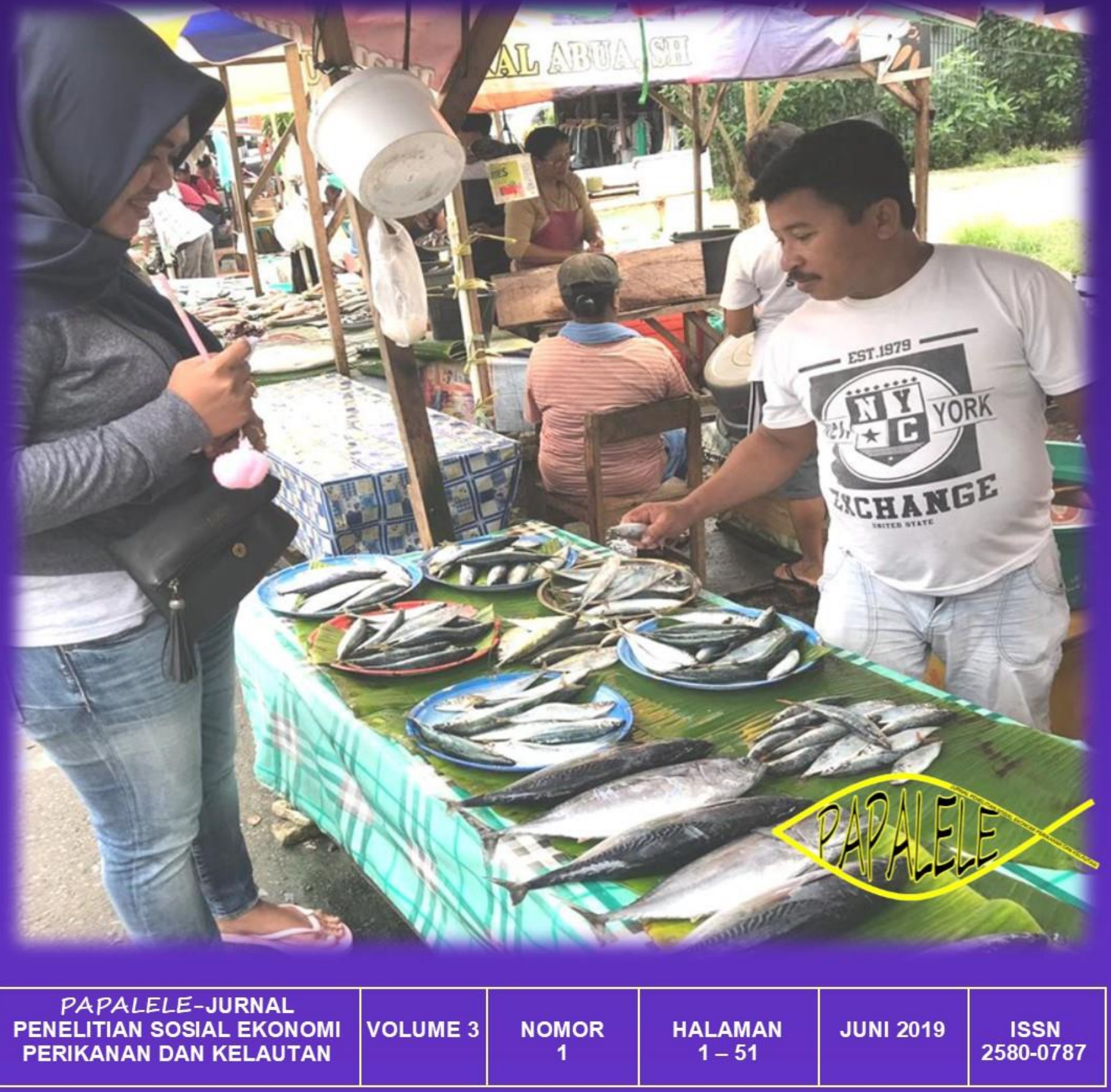

Diterbitkan oleh:

F 5 PROGRAM STUDI AGRIBISNIS PERIKANAN

mings FAKULTAS PERIKANAN DAN ILMU KELAUTAN 


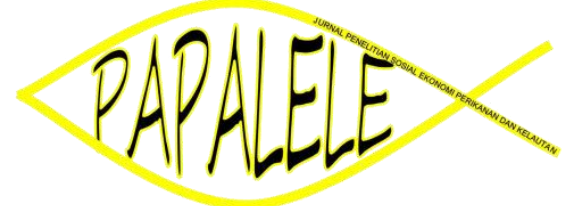

\section{JURNAL \\ PENELITIAN SOSIAL EKONOMI PERIKANAN DAN KELAUTAN}

\author{
PENANGGUNG JAWAB \\ Ketua Program Studi Sosial Ekonomi Perikanan \\ KETUA DEWAN REDAKSI \\ D. Bawole
}

RADAKTUR AHLI

V. Nikijuluw, M.S. Baskoro, J. Hiariej, F. Rieuwpassa, P. Wenno

REDAKTUR PELAKSANA

St. M. Siahainenia, R.L. Papilaya, Y. Lopulalan, Y.M.T.N. Apituley, V.J. Pical, W. Talakua, E. Talakua

PELAKSANA TATA USAHA

L.M. Soukotta, A. Ruban, K. Pattimukay, J. Sangaji, F. de Lima

PENERBIT

Program Studi Sosial Ekonomi Perikanan Jurusan Agrobisnis Perikanan

Fakultas Perikanan dan Ilmu Kelautan Universitas Pattimura

\section{ALAMAT REDAKTUR}

Program Studi Sosial Ekonomi Perikanan Jurusan Agrobisnis Perikanan Fakultas Perikanan dan Ilmu Kelautan Universitas Pattimura

Jln. Mr. Chr. Soplanit Poka-Ambon Telp. (0911) 379859. Fax 379196

PAPALELE merupakan jurnal penelitian ilmu sosial ekonomi perikanan dan kelautan yang menyajikan artikel tentang hasil penelitian yang berkaitan dengan bidang sosial ekonomi perikanan dan kelautan. Setiap naskah yang dikirim akan dinilai secara kritis oleh tim penilai yang relevan sebelum diterbitkan. Jurnal ini diterbitkan dua kali setahun, bulan Juni dan Desember. 


\section{KATA PENGANTAR}

Puji dan syukur kami panjatkan kepada Tuhan Yang Maha Esa atas rahmat-Nya. Jurnal PAPALELE, Jurnal penelitian Sosial Ekonomi Perikanan dan Kelautan kembali diterbitkan.

PAPALELE, Jurnal penelitian Sosial Ekonomi Perikanan dan Kelautan sesuai dengan Keputusan Lembaga Ilmu Pengetahuan Indonesia Nomor 0005.25800787/JI.3.1.SK.ISSN/2017.0529 Mei 2017 telah mengeluarkan nomor ISSN 2580-0787 untuk mulai penerbitan edisi volume 1 nomor 1, Juni 2017, dan sekarang melanjutkan perebitan untuk edisi volume 3 nomor 1, Juni 2019. Pada edisi ini, sama seperti edisi sebelumnya ditampilkan lima tulisan penelitian yang berkaitan dengan ilmu sosial ekonomi perikanan dan kelautan.

Dengan diterbitkannya jurnal ini, diharapkan dapat memberikan informasi ilmiah di bidang sosial ekonomi perikanan dan kelautan kepada pembaca. Saran dan masukan dari pembaca sangat diharapkan guna kesempurnaan penerbitan jurnal di waktu depan.

$\underline{\text { REDAKSI }}$ 


\section{DAFTAR ISI}

Halaman

KATA PENGANTAR

DAFTAR ISI ii

EFISIENSI TEKNIS DAN EKONOMI PERIKANAN TUNA HAND LINE DI NEGERI TIAL KABUPATEN MALUKU TENGAH

Oleh: Priscyllia Franetha Siahainenia, Dionisius Bawole, dan Willem Talakua $1-10$

ANALISIS KELAYAKAN USAHA KERAMBA JARING APUNG (KJA) DENGAN SISTEM MONOKULTUR DAN POLIKULTUR DI TANJUNG MARTHAFONS KOTA AMBON

Oleh: Tiffany Evangeline Leatemia

KELAYAKAN USAHA POLE AND LINE DI NEGERI HATIVE KECIL KOTA AMBON

Oleh: Ferdinan W. M. Haulussy

PRODUKTIVITAS DAN RESIKO USAHA PERIKANAN PURSE SEINE

DI NEGERI LATUHALAT

Oleh: Robert Frento Pattipeilohy dan Eygner Gerald Talakua

EFISIENSI DAN KEBERLANJUTAN USAHA PURSE SEINE DI KABUPATEN MALUKU TENGAH DAN KOTA AMBON

Oleh: Margie Wattimury 


\title{
EFISIENSI TEKNIS DAN EKONOMI PERIKANAN TUNA HAND LINE DI NEGERI TIAL KABUPATEN MALUKU TENGAH
}

\section{TECHNICAL AND ECONOMIC EFFICIENCY OF TUNA HAND LINE FISHERIES IN TIAL VILLAGE, CENTRAL MALUKU REGRENCY}

\author{
Priscyllia Franetha Siahainenia, Dionisius Bawole*), dan Willem Talakua \\ Program Studi Agrobisnis Perikanan, FPIK, Universitas Pattimura \\ *) Penulis korespondensi: dion_bawole@yahoo.com \\ Diterima 29 Juli 2019, disetujui 2 September 2019
}

\begin{abstract}
ABSTRAK
Sumberdaya pelagis besar termasuk ikan tuna (Thunnus sp) di perairan Maluku cukup potensial dengan status moderate, namun harus dimanfaatkan secara optimal. Nelayan di Negeri Tial memanfaatkan sumberdaya tersebut menggunakan Alat Penangkapan Ikan (API) hand line, tipe pancing ulur. Tuna hand line, tergolong perikanan skala kecil dengan berbagai persoalan terutama alokasi fishing input yang mengarah pada ketidak efisiensi. Penelitian ini secara umum bertujuan untuk menganalisis usaha perikanan tuna hand line berbasis efisiensi teknis dan ekonomi. Penelitian ini menggunakan metode pendekatan survei, dengan jumlah sebanyak 20 unit hand line. Lokasi penelitian adalah Negeri Tial Kabupaten Maluku Tengah. Analisis data menggunakan teknik pendekatan fungsi produksi Cobb-Douglas untuk mengidentifikasi input yang efisien; beberapa parameter finansial untuk menentukan kelayakan usaha; dan CPUE untuk mengukur tingkat produktivitas teknis. Hasil menunjukkan bahwa faktor produksi yang efisien adalah pengalaman melaut dan frekwensi melaut. Selama empat bulan pengamatan, seluruh unit usaha memperoleh keuntungan rata-rata mencapai Rp. 31.199 .139 atau Rp. 458.810,86/trip. Berdasarkan parameter $\mathrm{R} / \mathrm{C}$ dan PP usaha layak dikembangkan, sedangkan ROI terbesar $(135,2 \%)$ berada pada unit usaha ke-18. Unit usaha yang memiliki CPUE > 1 terdapat pada unit ke-1; ke-2; ke-3; ke-5; ke-6; ke-9; ke-11; ke-12; ke-13; ke-14; ke-15; ke-9; ke-16; ke-17; ke-18; ke-19 dan ke-20. Berdasarkan beberapa pengukuran teknis-ekonomi, maka usaha perikanan tuna hand line di Negeri Tial efisien secara teknis dan ekonomi sehingga layak dikembangkan.
\end{abstract}

Perikanan tuna hand line, efisiensi teknis-ekonomi, Negeri Tial

\section{ABSTRACT}

The resources of large pelagic including tuna (Thunnus sp) in Maluku are quite potential with moderate status and must be utilized optimally. In Tial, the utilizing of these resources uses hand lines; especially fishing line. Tuna hand line is classified as small-scale fisheries which has various problems. One of it is fishing inputs allocation that leads to inefficient. This study in general aims to analyze the hand line tuna fisheries business based on technical and economical efficiency. It was conducted by using survey method in Tial, Central Maluku Regency for 20 units hand line fishermen. Data was analized by Cobb-Douglas production function approach to identify efficient inputs; several financial parameters to determine business feasibility; and CPUE to measure the level of technical productivity. The results show that efficient production factors are fishermen's fishing experience and fishing frequency. During the four months of observation, all business units made an average profit of $R p$ 31,199,139 or $R p$ 458,810.86/trip. $R / C$ and PP parameters show that the business is feasible to be developed; while the largest ROI (135.2\%) is in the $18^{\text {th }}$ business unit. Business units that have CPUE $>1$ are unit $1^{\text {st }}, 2^{\text {nd }}, 3^{\text {rd }}, 5^{\text {th }}, 6^{\text {th }}, 9^{\text {th }}, 11^{\text {th }}, 12^{\text {th }}$, $13^{\text {th }}, 14^{\text {th }}, 15^{\text {th }}, 16^{\text {th }}, 17^{\text {th }}, 18^{\text {th }}, 19^{\text {th }}$ and $20^{\text {th }}$. Based on several technical-economical measurements, the hand line tuna fishery business in Tial is efficient and feasible to be developed.

Kata kunci: tuna hand line fisheries, technical-economical efficiency, Tial 


\section{PENDAHULUAN}

Wilayah Pengelolaan Perikanan (WPP) perairan Maluku, mengandung berbagai sumberdaya perikanan, seperti: pelagis besar, pelagis kecil, demersal, ikan karang konsumsi, udang penaeid, lobster, dan cumi-cumi. Berdasarkan data, jenis ikan pelagis besar termasuk tuna (Thunnus $\mathrm{sp}$ ) masih bisa dimanfaatkan karena underexploited (Sudirman $d k k$. 2017). Negeri Tial Kabupaten Maluku Tengah merupakan salah satu sentral penangkapan tuna hand line jenis pancing ulur. Penangkapan tuna pada wilayah tersebut, kemajuannya sangat pesat.

Namun secara faktual, perikanan tuna hand line di Tial menggunakan teknologi penangkapan sangat sederhana sehingga nelayan sulit menjangkau daerah penangkapan (fishing ground) yang jauh, khususnya pada saat gelombang besar, sehingga produksi tangkapan tidak sesuai dengan harapan. Tingginya harga tuna memicu nelayan melakukan penangkapan sepanjang tahun tanpa memperhatikan musim penangkapan. Penambahan upaya penangkapan menimbulkan kenaikan harga input, khususnya BBM dan apabila tidak dibarengi dengan kenaikan produksi, maka usaha mengalami kerugian (collaps).

Bertolak dari persoalan yang dikemukakan di atas, muncul pertanyaan sejauh mana pelaku usaha/nelayan tuna hand line di Tial menerapkan prinsip efisiensi dalam mengelola usahanya? Dengan demikian, perlu adanya suatu kajian secara komprehensif dan ilmiah melalui penelitian yang diberi judul "Efisiensi Teknis dan Ekonomi Perikanan Tuna Hand Line".

\section{METODE PENELITIAN}

Penelitian ini menggunakan teknik diskrptif dengan pendekatan metode survei. Pengumpulan data primer menggunakan daftar pertanyaan, sedangkan data sekunder melalui beberapa instansi yang terkait dengan penelitian ini. Cara menarik contoh menggunakan teknik purposive sampling (Sarwono 2006). Populasi berjumlah 60 unit, digunakan sebanyak 20 unit sebagai contoh dengan pertimbangan: usaha kontinyu dalam berproduksi; masih aktif saat penelitian berlangsung serta data tersedia. Data dan penggunaannya (Tabel 1).

Tabel 1. Data dan Peruntukannya

\begin{tabular}{|c|c|c|c|c|}
\hline Tujuan penelitian & $\begin{array}{l}\text { Jenis } \\
\text { data }\end{array}$ & Analisis & Model & Hasil \\
\hline $\begin{array}{l}\text { Profil usaha perikanan } \\
\text { tuna hand line secara } \\
\text { teknis- ekonomi }\end{array}$ & Primer & Diskriptif & Kualitatif & $\begin{array}{l}\text { Profil usaha perikanan tuna } \\
\text { hand line secara teknis- } \\
\text { ekonomi }\end{array}$ \\
\hline $\begin{array}{l}\text { Menganalisis input } \\
\text { terhadap output }\end{array}$ & $\begin{array}{l}\text { Primer: } \\
\text { - Produksi } \\
\text { - Faktor } \\
\text { produksi }\end{array}$ & $\begin{array}{l}\text { - Koefisien } \\
\text { determinasi } \\
\text { - Uji overall } \\
\text { - Uji partial }\end{array}$ & $\begin{array}{l}\text { Fungsi } \\
\text { produksi } \\
\text { Cobb- } \\
\text { Douglas }\end{array}$ & $\begin{array}{l}\text { Efisiensi input terhadap } \\
\text { output }\end{array}$ \\
\hline $\begin{array}{l}\text { Menentukan kelayakan } \\
\text { finansial usaha }\end{array}$ & $\begin{array}{l}\text { Primer: } \\
\text { - Harga } \\
\text { - Produksi } \\
\text { - Biaya }\end{array}$ & $\begin{array}{l}\text { - Penerimaan } \\
\text { - Biaya } \\
\text { - Investasi }\end{array}$ & $\begin{array}{l}\mathrm{R} / \mathrm{L} \\
\mathrm{R} / \mathrm{C} ; \\
\mathrm{PP} ; \text { dan } \\
\text { ROI }\end{array}$ & Kelayakan finansial usaha \\
\hline $\begin{array}{l}\text { Mengukur tingkat } \\
\text { produktivitas teknis }\end{array}$ & $\begin{array}{l}\text { Primer: } \\
\text { - Produksi } \\
\text { - Upaya }\end{array}$ & $\begin{array}{l}\text { Rasio } \\
\text { produksi dan } \\
\text { upaya }\end{array}$ & CPUE & Produktivitas teknis \\
\hline
\end{tabular}

Berikut ini merupakan beberapa formula dalam analisis kuantitatif, sebagai berikut:

1) Cobb-Douglas:

$$
\begin{gathered}
Y=a X_{1}^{b 1} X_{2}^{b 2} \ldots X_{i}^{b i} \ldots X_{n}^{b n} e^{\mu} \\
Y=\text { Produksi tangkapan }
\end{gathered}
$$

$$
\begin{aligned}
X_{1} \ldots X_{n} & =\text { Faktor produksi atau input } \\
a & =\text { Konstanta } \\
b & =\text { Koefisien regresi atau elastisitas } \\
\text { produksi } &
\end{aligned}
$$




$$
\begin{aligned}
\mu & =\underset{\text { Tingkat kesalahan (disturbance }}{\text { term) }} \\
e & =\text { Logaritma natural }
\end{aligned}
$$

Dalam memudahkan penggunaan fungsi produksi Cobb-Douglas, digunakan regresi berganda (Soekartawi 1997) dalam bentuk persamaan:

$Y=a+b_{1} X_{1}+b_{2} X_{2}+\ldots+b_{n} X_{n}+e^{\mu}$

Pendugaan dalam bentuk linear berganda diubah dengan menggunakan logaritma, sehingga persamaan (2) berubah menjadi;

$\log Y=a+b_{1} \log X_{1}+b_{2} \log X_{2}+\ldots+$ $b_{n} \log X_{n}+v$

Estimasi faktor produksi terhadap produksi, di mana:

$$
\begin{aligned}
& Y=\text { Hasil tangkapan }(\mathrm{Kg} / 4 \text { bulan } \\
& \text { pengamatan) } \\
& X_{1}=\text { Biaya penangkapan }(\mathrm{Rp} / 4 \text { bulan } \\
& \text { pengamatan) } \\
& X_{2}=\text { Pengalaman melaut (Tahun) } \\
& X_{3}=\text { Frekwensi melaut (Trip/4 bulan } \\
& \text { pengamatan) } \\
& X_{4}=\text { Pendidikan non formal (Kali } \\
& \text { kegiatan) }
\end{aligned}
$$

Menentukan model persamaan regresi berganda, melalui koefisien determinasi $\left(\mathrm{R}^{2}\right)$; selanjutnya dilakukan uji-t (parsial test); dan uji-F (overall test).

Dalam uji-t perlu diperhatikan bentuk hipotesa yang dirumuskan tentang kedua populasi mean yang diinginkan, sebagai berikut:

a. Hipotesa nol $\left(\mathrm{H}_{0}\right)$ : seluruh variabel independen $\left(X_{1} \ldots X_{n}\right)$ tidak berpengaruh secara signifikan terhadap variabel dependen $(Y)$. Tingkat kepercayaan yang digunakan adalah $95 \%$ atau nilai $\propto=$ 0,05 ; dan

b. Hipotesa alternatif $\left(\mathrm{H}_{\mathrm{A}}\right)$ : seluruh variabel independen $\left(X_{1} \ldots X_{n}\right)$ berpengaruh secara signifikan terhadap variabel dependen (Y). Tingkat kepercayaan yang digunakan adalah $95 \%$ atau nilai $\propto=$ 0,05 .

Dasar pengambilan keputusan uji-t:

a. $\mathrm{H}_{0}$ diterima dan $\mathrm{H}_{\mathrm{A}}$ ditolak jika nilai $\mathrm{t}$ hitung $<\mathrm{t}$ tabel atau signifikasi $<0,05$;

b. $\mathrm{H}_{0}$ ditolak dan $\mathrm{H}_{\mathrm{A}}$ diterima jika nilai $\mathrm{t}$ hitung $>\mathrm{t}$ tabel atau siginifikan $>0,05$.

Dasar pengambilan keputusan dalam uji-F: a. Jika nilai signifikan $<0,05$ maka variabel independen secara bersamasama berpengaruh signifikan terhadap variabel dependen;

b. Jika nilai signifikan $>0,05$ maka variabel independen secara bersamasama tidak berpengaruh signifikan terhadap variabel dependen.

2) Analisis kelayakan usaha berdasarkan beberapa parameter finansial, diantaranya:

a. Analisis keuntungan menggunakan pendekatan teknik income statement (Irawati, 2007), berdasarkan formula:

$\pi=T R-T C$

$T R$ dan $T C$ pada persamaan diturunkan, sebagai berikut

$T R=Y . P y$

$T C=T F C+T V C$

di mana:

$\Pi=$ Keuntungan (Rp/4 bln peng.)

$\mathrm{TR}=$ Total penerimaan $(\mathrm{Rp} / 4 \mathrm{bln}$ peng.)

$\mathrm{TC}=$ Total Biaya (Rp/4 bln peng.)

$\mathrm{Y}=$ Produksi (Kg/4 bln peng.)

$\mathrm{Py}=$ Harga produk $(\mathrm{Rp} / \mathrm{kg})$

$\mathrm{FC}=$ Biaya tetap (Rp/4 bln peng.)

$\mathrm{VC}=$ Biaya variabel (Rp/4 bln peng.)

Kriteria penilaian:

Jika TR > TC, maka usaha memperoleh keuntungan;

Jika TR < TC, maka usaha menderita kerugian; dan

Jika TR $=$ TC, maka usaha mengalami pulang pokok.

b. Perhitungan biaya penyusutan (depreciation cost) menggunakan formula yang dikemukakan oleh Baridwan (2010)

$D=\frac{c-s}{n}$

di mana:

$\mathrm{D}=$ Nilai Depresiasi (Rp/tahun)

$\mathrm{C}=$ Harga beli (Rp)

$\mathrm{S}=$ Nilai sisa $(\mathrm{Rp})$

$\mathrm{n}=$ Umur ekonomis (Tahun)

c. Analisis R/C untuk melihat keuntungan usaha secara relatif dalam satuan waktu terhadap biaya yang digunakan. Rumusnya (Firdaus 2012), sebagai berikut:

$R / C=\frac{T R}{T F C+T V C}$ 
Kriteria penilaian:

a. Jika R/C > 1, maka usaha
$\begin{aligned} & \text { menguntungkan } \\ & \text { dikembangkan }\end{aligned}$

b. Jika $\mathrm{R} / \mathrm{C}<1$, maka usaha tidak menguntungkan dan tidak layak

c. Jika $\mathrm{R}=\mathrm{C}$, maka usaha tidak untung dan tidak rugi

d. Analisis PP bertujuan untuk mengevaluasi waktu pengembalian modal dari pendapatan atau benefit yang diperoleh. Rumus yang digunakan (Firdaus 2012), sebagai berikut:

$P P=\frac{\text { Investasi }}{\text { Benefit }}$

Kriteria penilaian:

a. Jika PP lebih kecil dari umur proyek maka usaha layak untuk dilanjutkan. Semakin kecil nilai PP maka usaha tersebut lebih layak.

b. Jika PP lebih besar dari umur proyek maka usaha tidak layak untuk dilanjutkan

e. Analisis ROI merupakan nilai keuntungan yang diperoleh pengusaha dari setiap jumlah uang yang diinvestasikan dalam periode waktu tertentu. Formulanya adalah sebagai berikut (Firdaus 2012):

$R O I=\frac{\text { Keuntungan }}{\text { Investasi }} \times 100 \%$

Kriteria penilaian:

Semakin besar ROI maka semakin besar kemampuan usaha untuk mengembalikan modal awal sehingga layak dikembangkan dan sebaliknya.

3. Analisis efisiensi teknis didekati melalui pengukuran produktivitas usaha yang dilakukan dengan membandingkan keluaran (output) dengan masukan (input) untuk setiap unit tangkap.. Penentuan produktivitas menggunakan teknik CPUE dengan rumus (Fauzi 2010), sebagai berikut:

$\mathrm{C} / \mathrm{E}$

di mana:

$\mathrm{C}=$ Cath/hasil tangkapan (Kg/4 bulan)

$\mathrm{E}=$ Effort/ upaya penangkapan (Trip/4 bulan).

\section{HASIL DAN PEMBAHASAN Profil Tekis}

Di Negeri Tial Kecamatan Salahutu, API tuna didominasi adalah pancing ulur (Rahmat dan Thamrin 2016). Umumnya, kapal yang digunakan terbuat dari fiberglass. Ukuran kapal yang digunakan untuk kegiatan penangkapan cukup bervariasi, dengan dimensi panjang (L) 7,6-9,3 meter, lebar (B) 11,5 meter, dan tinggi (D) 0,6-0,9 cm. Kapal pancing ulur mempunyai 1 palka berukuran panjang 1,0 meter; lebar 1 meter; dan tinggi 0,7 meter yang terdapat pada bagian haluan dan berfungsi untuk menyimpan es dan dapat menampung $100 \mathrm{~kg}$ hasil tangkapan. Alat tangkap pancing ulur, konstruksinya terdiri dari bahan tali (senar) utama, tali cabang mata pancing, kili-kili dan pemberat. Tali utama menggunakan nylon monofilament merek Dolpin nomor 90, 80 atau 70 sedangkan tali cabang dari nylon monofilament merek Superwata nomor 150 dan panjangnya 14 meter. Mata pancing yang digunakan adalah jenis tuna hook 05 atau 06.

Sistem penangkapan tuna adalah one day fishing. Jarak tempuh antara fishing porth dengan fishing ground berkisar 1,5 hingga 2 jam. Tujuan daerah penangkapan adalah Laut Banda yaitu perairan sekitar Pulau Nusalaut. Pada saat pemancingan, mata pancing dilengkapai dengan umpan, berupa cumi-cumi (Lolilgo sp), ikan momar atau layang (Decapterus sp), atau ikan terbang (Fam. Exocoetidae). Cumi-cumi untuk ikan umpan ditangkap nelayan sendiri dengan menggunakan alat tangkap pancing khusus unuk menangkap cumi-cumi.

Waktu penangkapan di laut berlangsung selama 13 jam yang dimulai pada pukul 02.00 sampai dengan pukul 15.00. Ratarata hasil tangkapan per trip per unit usaha mencapai 2 ekor atau $32 \mathrm{~kg}$ hingga 4 ekor atau $64 \mathrm{~kg}$. Satuan ini disesuaikan dengan ukuran ikan. Ikan tuna hasil tangkapan langsung di proses di atas perahu dan dijadikan tuna loin, yang mana bagian punggung ikan disebut loin laki-laki sedangkan bagian bawah disebut loin perempuan. Daging satu ekor ikan tuna dijadikan 4 (empat) potong, yaitu 2 (dua) bagian loin laki-laki dan 2 (dua) bagian loin perempuan. Kemudian tuna loin dimasukkan ke dalam palkah dan selanjutnya untuk 
mempertahankan mutu ikan diberi hancuran es.

Menurut Merta $d k k$. (2004), musim penangkapan ikan tuna dan cakalang di Laut Banda dengan menggunakan alat tangkap rawai tuna berlangsung pada bulan September hingga Maret. Pada saat musim tangkapan, seorang nelayan tuna rawai dapat menangkap ikan sebanyak 6 hingga 10 ekor per minggu sedangkan tidak musim ikan 1 hingga 2 ekor. Berdasarkan pengamatan, data produksi dan upaya penangkapan yang diilustrasikan sesuai waktu penelitian yaitu Oktober, November, Desember 2018, dan Januari 2019 (Gambar 1).

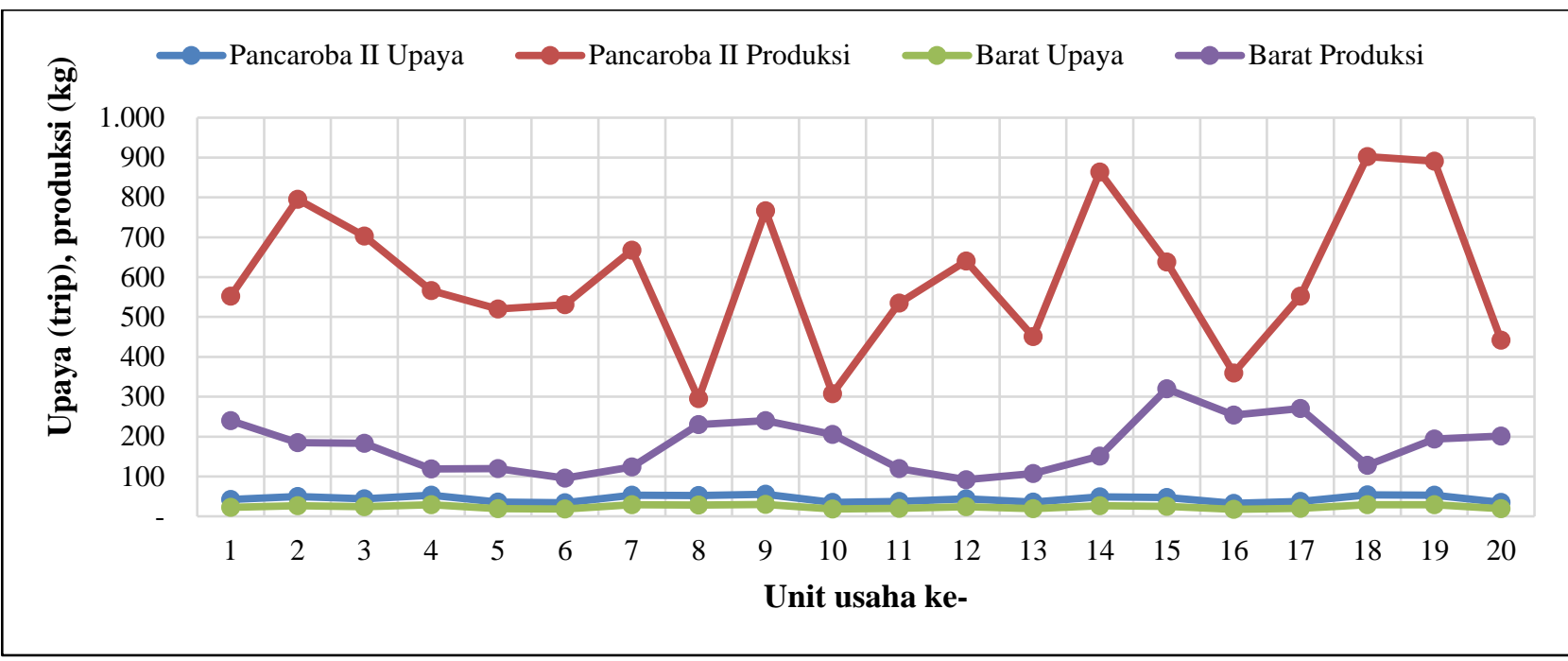

Gambar 1. Fluktuasi Upaya Dan Produksi Menurut Musim Penangkapan

\section{Profil Ekonomi}

Profil ekonomi yang dikaji menyangkut konsekwensi pengeluaran yang terkait dengan pengadaan barang modal/investasi dan pembiayaan penangkapan (biaya variabel dan biaya tetap). Tabel 2, menunjukkan besaran modal/unit.

Tabel 2. Besaran investasi pada perikanan tuna hand line di Tial

\begin{tabular}{cccccc}
\hline $\begin{array}{c}\text { Unit usaha } \\
\text { ke- }\end{array}$ & $\begin{array}{c}\text { Memulai } \\
\text { usaha } \\
\text { (Tahun) }\end{array}$ & $\begin{array}{c}\text { Nilai investasi } \\
(\mathbf{R p})\end{array}$ & $\begin{array}{c}\text { Unit usaha } \\
\text { ke- }\end{array}$ & $\begin{array}{c}\text { Memulai } \\
\text { usaha } \\
\text { (Tahun) }\end{array}$ & $\begin{array}{c}\text { Nilai investasi } \\
\text { (Rp) }\end{array}$ \\
\hline 1 & 2007 & 39.035 .000 & 11 & 2009 & 41.385 .000 \\
2 & 2007 & 34.897 .000 & 12 & 2014 & 37.310 .000 \\
3 & 2009 & 36.507 .000 & 13 & 2012 & 40.040 .000 \\
4 & 2009 & 24.647 .000 & 14 & 2009 & 35.110 .000 \\
5 & 2009 & 34.871 .000 & 15 & 2009 & 38.560 .000 \\
6 & 2008 & 38.740 .000 & 16 & 2014 & 41.900 .000 \\
7 & 2008 & 38.882 .000 & 17 & 2015 & 33.210 .000 \\
8 & 2008 & 38.882 .000 & 18 & 2007 & 32.015 .000 \\
9 & 2007 & 40.550 .000 & 19 & 2012 & 58.350 .000 \\
10 & 2015 & 58.940 .000 & 20 & 2009 & 51.155 .000 \\
\hline \multicolumn{7}{c}{ Total } & & $386.186 .000,00$ & \multicolumn{3}{c}{ Total } \\
\hline
\end{tabular}

Sumber: Hasil olahan data primer, 2019

Berdasarkan dimensi rata-rata investasi/unit untuk pengadaan peralatan utama sebesar $\quad$ Rp. 39.347.800,- dengan persentase sebagai berikut: kapal atau body $(36,42 \%)$; mesin $(61,90 \%)$; alat pancing $(1,38 \%)$; dan kompas $(0,31 \%)$ sedangkan peralatan pembantu sebesar Rp 413.250,- dengan persentase, antara lain: box Styrofoam $(65,76 \%)$; pisau ukuran besar $(13,67)$; gancu (14,52\%); dan lampu blitz (6,05\%). Dari total investasi sebesar Rp. 39.761.050,-/unit, pengeluaran untuk pengadaan peralatan utama sebesar Rp. 39.347.800,- atau 98,96\% sedangkan peralatan pembantu sebesar 
Rp. 413.250,- atau 1,04\%. Hal ini mengindikasikan bahwa porsi nilai peralatan utama lebih tinggi dibandingkan peralatan pembantu.

Berdasarkan hasil perhitungan, pengeluaran selama waktu pengamatan, terindikasi bahwa rata-rata biaya variabel yang dikeluarkan sebesar Rp. 12.159.496,75. Dari nilai tersebut, persentase pengeluaran berturutturut: BBM (55\%); ransum (30\%); es (10\%); dan batu (5\%) (Gambar 2). Jika biaya variabel dikonversikan per bulan adalah sebesar Rp. 3.039.874,19 atau Rp. 179.739,67/trip. Pengeluaran rata-rata biaya tetap adalah sebesar Rp. 1.752.881,81. Persentase pengeluarannya sebagai berikut: penyusutan sebesar Rp. 1.135.122,31 atau 64,76\%; pemeliharaan Rp. 451.092,50 atau 25,73\%; dan kontribusi keagamaan Rp. 166.667 atau 9,51\% (Gambar 3).

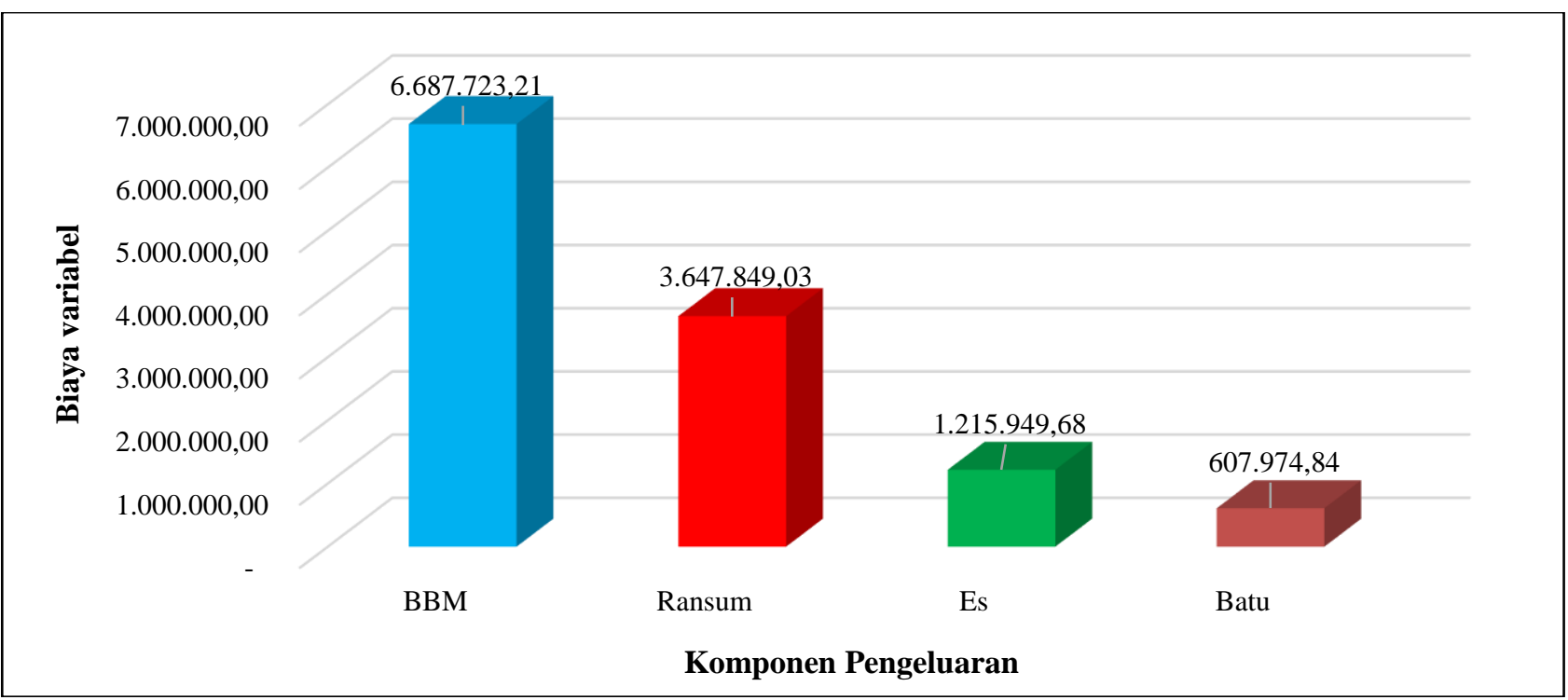

Gambar 2. Komponen Biaya Variabel dan Nilainya

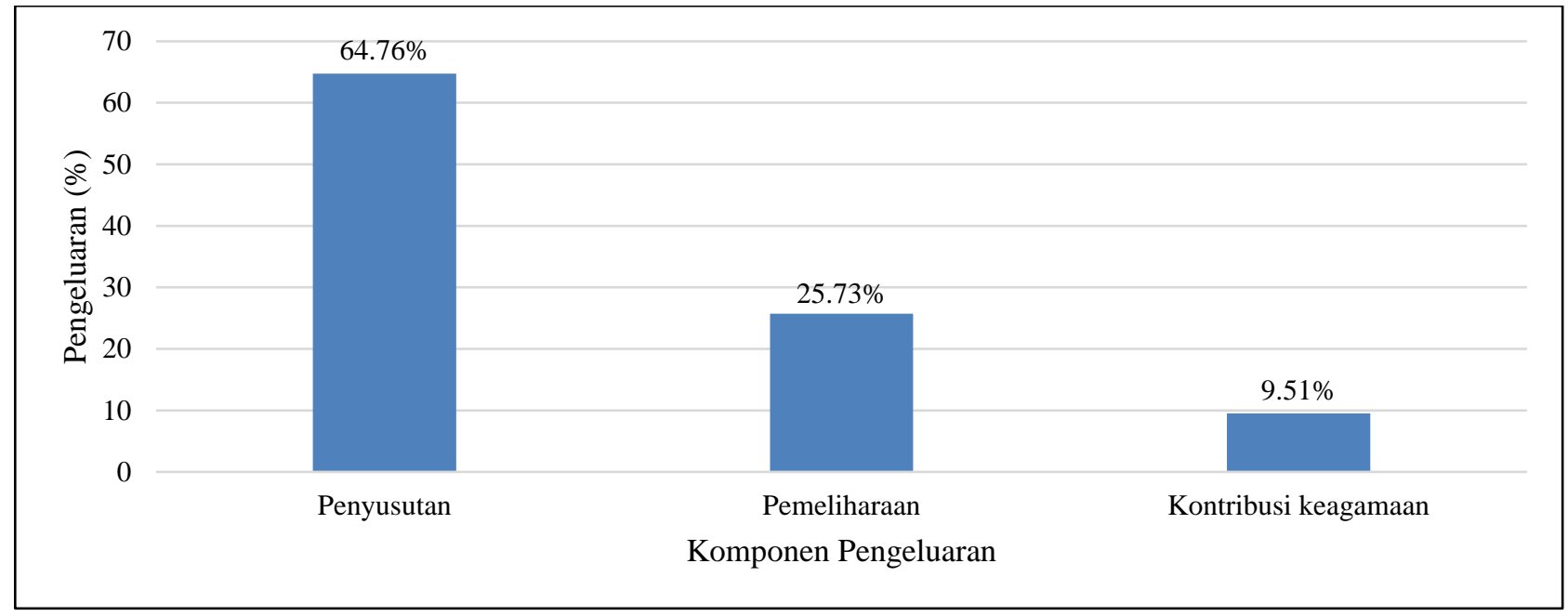

Gambar 3. Komponen Biaya Tetap dan Persentase Pengeluaran

\section{Analisis Faktor Produksi}

Berdasarkan analisis model FP-CD dengan menggunakan teknik regresi berganda (multi-regression), diperoleh hasil seperti yang tercantum pada Tabel 3. 
Tabel 3. Taksiran Koefisien Regresi FP-CD Pada Perikanan Tuna Hand Line di Tial

\begin{tabular}{llccccc}
\hline $\begin{array}{c}\text { Variabel } \\
\text { bebas }\end{array}$ & \multicolumn{1}{c}{ Uraian } & $\begin{array}{c}\text { Koefisien } \\
\text { regresi }\end{array}$ & Sig. & t-tabel & F-hitung & F-tabel \\
\hline $\log \varnothing$ & Konstanta & 4,138 & 0,10 & 2.093 & 161.327 & 3.06 \\
$\log X_{1}$ & Biaya penangkapan & 0,033 & 0,732 & & & \\
$\log X_{2}$ & Pengalaman melaut & 0,703 & $0,00^{* *}$ & & \\
$\log X_{3}$ & Frekwensi melaut & 0,204 & $0,009^{* *}$ & & \\
$\log X_{4}$ & Pendidikan non formal & $-0,053$ & 0,112 & & &
\end{tabular}

Sumber: Hasil olahan data primer, 2019

Koefisien determinasi $\left(\mathrm{R}^{2}\right)$ adalah 0,977

** Berpengaruh sangat nyata (tingkat signifikasi 95\%)

Berdasarkan Tabel 3, diperoleh model regresi berganda: $\quad Y=4.183+0.03 X_{1}+$ $0.703 X_{2}+0.204 X_{3}-0.53 X_{4}$. Besarnya koefisien determinasi $\left(\mathrm{R}^{2}\right)$ dapat digunakan untuk menunjukkan sampai seberapa jauh variasi variabel dependen $(Y)$ dijelaskan oleh variabel independen atau variasi produksi $(X)$ dapat diterangkan oleh parameter faktor produksi $X_{1}, X_{2}, X_{3}, X_{4}$ sebesar $97,7 \%$, sedangkan sisanya $2,3 \%$ tidak dapat diterangkan oleh variasi faktor produksi yang lain, seperti cuaca atau faktor iklim yang tidak dimasukan dalam model.

Hasil uji-t terdapat 2 (dua) variabel input yakni: pengalaman melaut $\left(X_{2}\right)$ dan frekwensi melaut $\left(X_{3}\right)$ berpengaruh terhadap peningkatan produksi. Berpengaruhnya kedua variabel independen, secara statistika berturutturut: $11.204>2.093$ dan $2.975>2.093$ pada tingkat signifikasi 95 persen (uji dua ekor atau two tails test). Variabel $X_{2}$ memiliki nilai koefisien regresi adalah 0,703, artinya kenaikan pengalaman melaut sebesar $1 \%$ akan meningkatkan produksi sebesar 70,3 persen, sedangkan koefisien regresi bernilai 0,204 $\left(X_{3}\right)$ memiliki arti kenaikan frekwensi melaut sebesar $1 \%$ dapat meningkatkan produksi sebesar 20,4 persen. Hasil uji-F terindikasi bahwa variabel input $\left(X_{1}-X_{4}\right)$ secara bersamasama berpengaruh terhadap variabel output (Y), yang teridikasi dari F-hitung > F-tabel atau $161,327>3,06$

Sumberdaya tuna termasuk jenis ikan pelagis besar dengan wilayah ruaya cukup jauh dan perenang cepat dengan kecepatan mencapai 80 km/jam (Nakamura 1991). Kehidupan tuna yang selalu bermigrasi dari satu tempat ke tempat yang lain menyebabkan nelayan sulit menentukan daerah penangkapan (fishing ground) yang tepat. Ketiadaan alat pendeteksi gerombolan ikan pada unit penangkapan hand line sehingga nelayan hanya mengandalkan pengalaman melaut dalam mencari ikan.

Karakter perikanan tangkap yang penuh dengan resiko karena luasnya daerah penangkapan berdampak pada akumulasi volume produksi yang tidak sesuai dengan harapan nelayan. Berdasarkan hasil estimasi faktor produksi diperoleh bahwa variabel pengalaman melaut yang merupakan faktor teknis penangkapan berkorelasi secara positif terhadap produksi, sehingga diharapkan pelaku usaha atau nelayan hand line di Negeri Tial dapat memperhatikan parameter dimaksud dalam pengambilan keputusan (decision variable) untuk meningkatkan produksi tangkap.

Berdasarkan hasil estimasi, frekwensi melaut merupakan variabel yang increasing productivity artinya kenaikan variabel independen tersebut meningkatkan variabel dependen atau produksi. Menurut Siahainenia (2016), frekwensi melaut linier dengan produksi, artinya bertambahnya frekwensi melaut dapat meningkatkan produksi tangkapan (kasus perikanan purse seine di Kecamatan Leihitu). Frekwensi melaut yang diukur dengan satuan trip dan berdasarkan data 4 (empat) bulan pengamatan, yaitu bulan Oktober, November, Desember 2018, dan Januari 2019 dengan rata-rata frekwensi melaut masing-masing: 20, 24, 10 dan 14 trip yang berkorelasi dengan volume produksi per bulan. Dengan demikian, faktor teknis berupa frekwensi melaut perlu dipertimbangkan 
pelaku usaha dalam upaya meningkatkan produksi dengan tetap menjaga keberlangsungan sumberdaya tuna.

\section{Analisis Finansial}

Analisis finansial pada bagian ini, menyangkut analisis keuntungan dengan pendekatan income statement, analisis parameter finansial lainnya, berupa $\mathrm{R} / \mathrm{C}$, PP dan ROI. Hasil analisis keuntungan diilustrasikan pada Gambar 4.
Gambar 4, mengindikasikan bahwa seluruh pengamatan yang berjumlah 20 unit perikanan hand line di Negeri Tial memperoleh keuntungan. Hal ini terindikasi atau TR > TC. Keuntungan tertinggi terdapat pada unit ke-19 (Rp. 46.450.751/4 bulan pengamatan) sedangkan terendah pada unit ke8 (Rp. 17.062.350/4 bulan pengamatan). Berdasarkan teknik pendekatan income statement, perikanan tuna hand line di Tial layak dikembangkan.

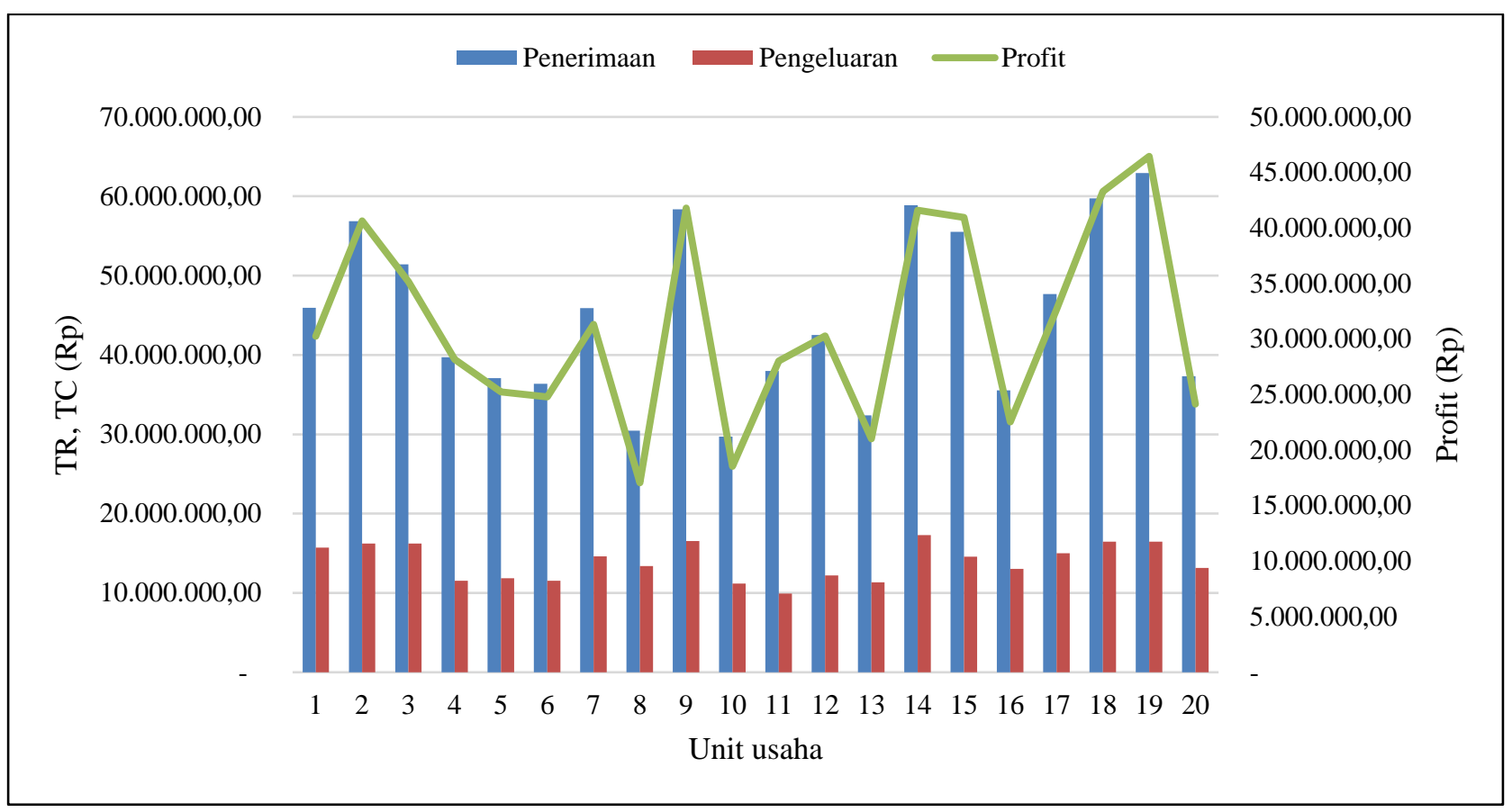

Gambar 4. Kurva Perbedaan TR, TC dan Profit Yang Diperoleh

Hasil analisis Rasio Revenue-Cost (R/C), Payback Period (PP) (Tabel 4) Komponen rasio $\mathrm{R} / \mathrm{C}$ dalam parameter finansial, setelah dihitung hasilnya mengindikasikan setiap unit usaha layak dikembangkan sebab R/C > 1. Rata-rata rasio/unit adalah sebesar 3,22, artinya untuk memperoleh penerimaan Rp.1,- membutuhkan total pengeluaran sebesar Rp. 3,22. Hasil perhitungan PP setiap unit memperlihatkan bahwa waktu pengembalian modal lebih rendah dari umur proyek yang diestimasi 5 (lima) tahun. Unit usaha ke-18 memiliki PP sebesar 0,74 merupakan unit yang waktu pengembalian modal terbaik dibandingkan dengan lainnya. Arti 0,74 adalah, unit ke-18 mengembalikan modal hanya dalam jangka waktu 9 bulan. Data ini menunjukkan bahwa unit usaha ke-18 memiliki nilai investasi relatif rendah sedangkan benefit cukup tinggi. Tingginya benefit dapat memicu pengembalian modal dalam waktu yang relatif singkat.

Berdasarkan Tabel 4, nilai ROI tertinggi berada pada unit usaha ke-18 yaitu sebesar 135,2\%. Berdasarkan kriteria, tingginya ROI menunjukkan kemampuan usaha dalam mengembalikan modal awal. Unit usaha tersebut memiliki keuntungan yang tinggi namun sebaliknya investasi atau modal awal yang rendah. Poin penting dari bahasan ini adalah bagaimana pelaku usaha/nelayan dapat mengatur atau mengelola input secara efisien untuk meraih keuntungan maksimal dalam upaya untuk mengembalikan modal awal. 


\section{Analisis Pengukuran Produktivitas}

Hasil analisis produktivitas teknik (Gambar 5), menunjukkan bahwa, terdapat beberapa unit usaha yang tidak produktif atau inefisien, diantaranya unit ke-4; ke-7; ke-8 dan ke 10, karena CPUE < 1, sedangkan yang lainnya dikatakan produktif. Arti produktif atau dengan kata lain efisien di mana penggunaan input secara optimal namun menghasilkan produksi maksimal. Sebagai contoh, CPUE tertinggi terdapat pada unit ke17 yaitu 1,42, artinya 1,42 persen dari produksi tuna per trip oleh nelayan hand line di Tial dihasilkan oleh unit ke-17. Jika yang terendah adalah unit usaha ke- 8 yaitu 0,66 bermakna 0,66 persen dari produksi tuna per trip dihasilkan oleh unit usaha ke-8.

Tabel 4. Nilai R/C, PP, dan ROI Pada Usaha Perikanan Tuna Hand Line di Tial

\begin{tabular}{|c|c|c|c|c|}
\hline \multirow{2}{*}{$\begin{array}{c}\text { Unit usaha } \\
\text { ke- }\end{array}$} & \multicolumn{3}{|c|}{ Parameter finansial } & \multirow[b]{2}{*}{ Keterangan } \\
\hline & $\mathrm{R} / \mathrm{C}$ & $\mathbf{P P}$ & $\begin{array}{c}\text { ROI } \\
(\%)\end{array}$ & \\
\hline 1 & 2,93 & 1,29 & 77,5 & Parameter R/C dan PP adalah layak \\
\hline 2 & 3,50 & 0,86 & 116,4 & Parameter R/C dan PP adalah layak \\
\hline 3 & 3,17 & 1,04 & 96,4 & Parameter R/C dan PP adalah layak \\
\hline 4 & 3,44 & 0,88 & 113,2 & Parameter R/C dan PP adalah layak \\
\hline 5 & 3,13 & 1,38 & 72,4 & Parameter R/C dan PP adalah layak \\
\hline 6 & 3,15 & 1,56 & 64,0 & Parameter R/C dan PP adalah layak \\
\hline 7 & 3,15 & 1,24 & 80,6 & Parameter R/C dan PP adalah layak \\
\hline 8 & 2,28 & 2,28 & 43,9 & Parameter R/C dan PP adalah layak \\
\hline 9 & 3,52 & 0,97 & 103,1 & Parameter R/C dan PP adalah layak \\
\hline 10 & 2,66 & 3,18 & 31,4 & Parameter R/C dan PP adalah layak \\
\hline 11 & 3,83 & 1,48 & 67,8 & Parameter R/C dan PP adalah layak \\
\hline 12 & 3,48 & 1,23 & 81,2 & Parameter R/C dan PP adalah layak \\
\hline 13 & 2,85 & 1,90 & 52,5 & Parameter R/C dan PP adalah layak \\
\hline 14 & 3,41 & 0,84 & 118,5 & Parameter R/C dan PP adalah layak \\
\hline 15 & 3,81 & 0,94 & 106,2 & Parameter R/C dan PP adalah layak \\
\hline 16 & 2,73 & 1,86 & 53,8 & Parameter R/C dan PP adalah layak \\
\hline 17 & 3,18 & 1,02 & 98,4 & Parameter R/C dan PP adalah layak \\
\hline 18 & 3,63 & 0,74 & 135,2 & Parameter R/C dan PP adalah layak \\
\hline 19 & 3,82 & 1,26 & 79,6 & Parameter R/C dan PP adalah layak \\
\hline 20 & 2,83 & 2,12 & 47,2 & Parameter R/C dan PP adalah layak \\
\hline
\end{tabular}

Sumber: Hasil olahan data primer, 2019

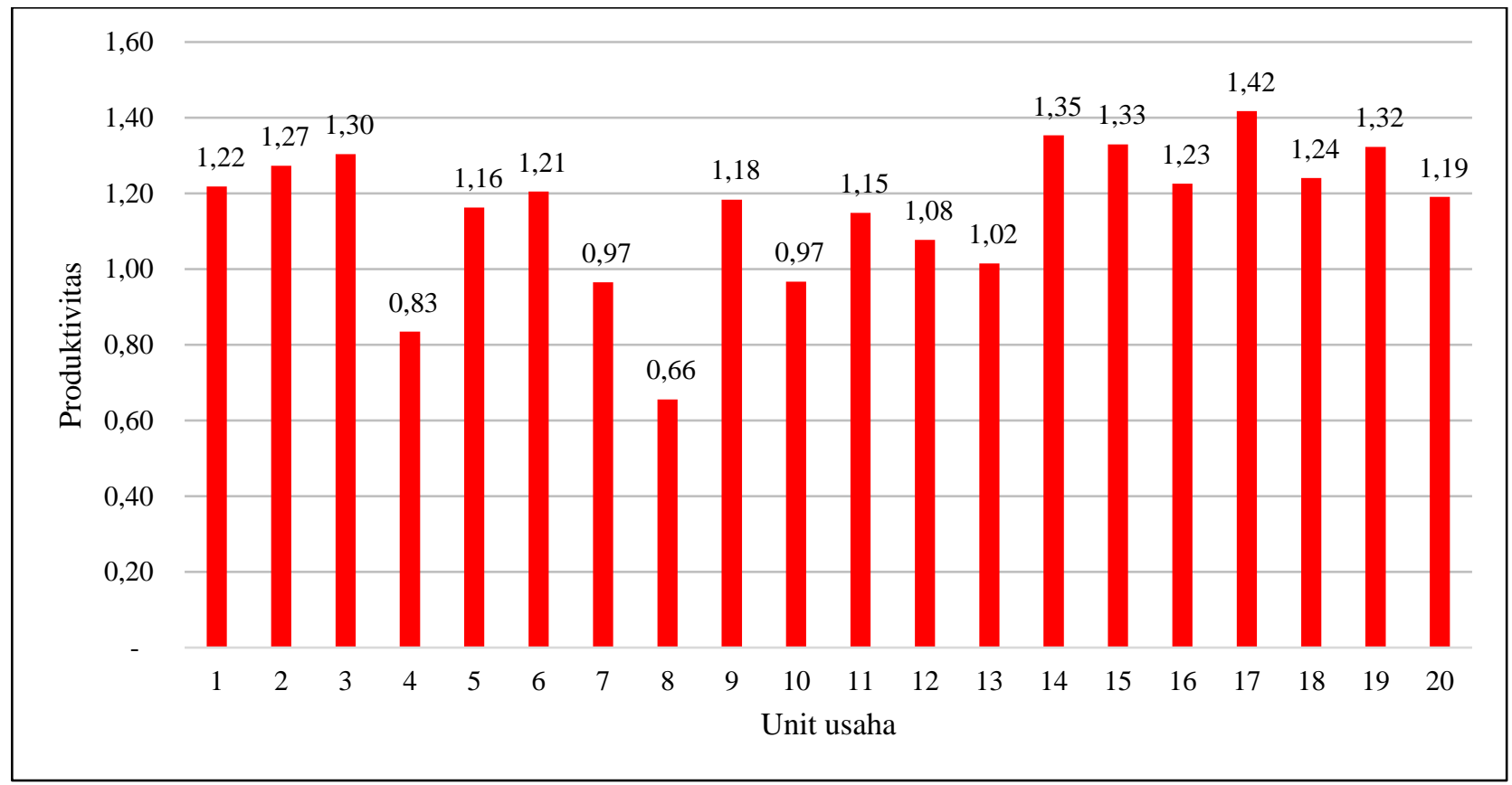

Gambar 5. Produktivitas Teknis Tuna Hand Line di Negeri Tial 
Berdasarkan data, dari 20 unit hand line di Negeri Tial, sebanyak $66,7 \%$ berada pada tingkat produktivitas teknis (CPUE > 1) sedangkan sisa 33,3\% inproduktif (CPUE < 1). Secara teori, perhitungan CPUE untuk mengetahui kelimpahan stok dan tingkat pemanfaatan sumberdaya perikanan pada suatu daerah tertentu (Gulland 1954). Terkait dengan hal tersebut terindikasi bahwa stok ikan tuna pada wilayah penangkapan hand line nelayan di Tial cukup melimpah untuk dimanfaatkan. Unit hand line yang tergolong inproduktif perlu menambah input berupa frekwensi melaut untuk mencapai produktivitas.

\section{KESIMPULAN}

1. Alat Penangkapan Ikan (API) Hand Line jenis pancing ulur di Tial berukuran Panjang (L) 7,6-9,3 M; Lebar (B) 1-1,5 M; dan tinggi (D) $0,6-0,9$ M. Rata-rata investasi mencapai $\mathrm{Rp}$. 39.761.050, sedangkan biaya variabel sebesar Rp. 12.159.496,75 dana biaya tetap Rp. 1.752.881,8.

2. Faktor Produksi yang berpengaruh terhadap peningkatan output adalah pengalaman melaut dan frekwensi melaut.

3. Rata-rata keuntungan usaha selama waktu pengamatan mencapai Rp. 31.199.139. Berdasarkan parameter R/C dan PP, usaha perikanan hand line secara finansial layak dikembangkan, sedangkan ROI terbesar berada pada unit ke-18 (135,2\%)

4. Pada 20 unit pengamatan terdapat 4 unit inproduktif (CPUE < 1), Unit Ke-4; Ke-\&7; dan Ke-8; dan Ke-10, yang lain tergolong produktif (CPUE > 1)

\section{SARAN}

1. Perlu adanya bantuan pemerintah berupa modal, dan biaya penangkapan untuk mengembangkan perikanan rakyat sebagai upaya peningkatan kesejahteraan nelayan.

2. Variabel yang teridentifikasi efisien, sebaiknya menjadi perhatian nelayan untuk mencapai penangkpan yang optimal demi keberlanjutan usaha.

3. Dalam mencapai tigkat produktifitas teknis, sebaiknya usaha tuna hand line menambah frekwensi melaut.
4. Diharapkan adanaya penelitian lanjutan dengan menambah durasi waktu pengamatan.

\section{DAFTAR PUSTAKA}

Baridwan, Z. 2010. Intermediate Accounting. Edisi Ketujuh. Badan Penerbit Fakultas Ekonomi Universitas Gajah Mada. Yogyakarta.

Fauzi A. 2010. Ekonomi Perikanan. Teori, Kebijakan, dan Pengelolaan. PT Gramedia Pustaka Utama, Jakarta. 124 hal.

Firdaus M. 2012. Manjemen Agribisnis. Penerbit Bumi Aksara, Jakarta. 221 hal.

Guland J.A. 1954. The Economics of a Common Property Resources; The Fishery.Journal Political Economy. Canada.

Irawati S. 2007. Akuntansi Dasar 1 dan 2. Penerbit Pustaka. Bandung. 430 hal.

Merta, I.G.S., B Sadhotomo, S.B. Atmaja dan Wudianto. 2004. Musim Penangkapan Ikan Pelagis dalam Musim Penangkapan Ikan di Indonesia. Balai Pendidikan Perikanan Laut. Pusat Riset Perikanan Tangkap. Badan Riset Kelautan dan Perikanan. Departemen Kelautan dan Perikanan.

Nakamura H. 1991. Ditemukan Tujuh Jenis Ikan Tuna. Bali Post 12 April 1991. Hal 10.

Rahmat E dan Thamrin I. 2016. Teknologi Penangkapan Ikan Tuna dengan Alat Pancing Ulur di Laut Banda oleh Nelayan Maluku. Buletin Teknik Litkayasa. Vol. 4 No. 1 Juni 2016

Sarwono. 2006. Metode Penelitian Kuantitatif dan Kualitatif. Penerbit Graha Ilmu Yogyakarta. 236 hal.

Siahainenia St.M. 2016. Determinasi Produksi dan Pendapatan Nelayan Purse Seine di Kecamatan Leihitu Kabupaten Maluku Tengah. Prosiding. Semnas Kelautan dan Perikanan ke-III. Kupang 27 Oktober 2016. Hal 195-201.

Sudirmnan H, Nelwan A, Kurnia M, Zainuddin M dan Nessa N. 2017. Perikanan Pelagis Besar (Tuna, 
Cakalang dan Tongkol). Penerbit Yarsif Watampone, Jakarta. 200 hal.

Soekartawi. 1997. Teori Ekonomi Produksi dengan Pokok Pembahasan Analisis Fungsi Produksi Cobb-Douglas. Manajemen PT RajaGrafindo Persada Jakarta. 257 hal. 


\section{PEDOMAN PENULISAN}

\section{Pedoman Umum}

a. PAPALELE, Jurnal Penelitian Ilmu Sosial Ekonomi Perikanan dan Kelautan memuat hasil penelitian yang berkaitan dengan bidang sosial ekonomi perikanan dan kelautan.

b. Naskah yang dikirim merupakan karya asli dan belum pernah diterbitkan atau dipublikasikan.

c. Naskah diketik dalam bahasa Indonesia yang baik dan benar, tidak diperkenankan menggunakan singkatan yang tidak umum.

d. Naskah diketik pada kertas A4 dengan menggunakan program microsoft word dengan 2 spasi, margin 2.5 $\mathrm{cm}$ (kiri), $2 \mathrm{~cm}$ (atas), $2 \mathrm{~cm}$ (bawah) dan 1,5 cm (kanan), font 12 times new roman, setiap halaman diberi nomor secara berurutan dengan berkolom 1 (satu), dikirim beserta soft copy maksimal 15 halaman.

e. Naskah dikirim melalui alamat ke redaksi pelaksana PAPALELE, Jurnal Penelitian Ilmu Sosial Ekonomi Perikanan dan Kelautan, Program Studi Sosial Ekonomi Perikanan Jurusan Teknologi Hasil Perikanan, Fakultas Perikanan dan Ilmu Kelautan, Universitas Pattimura, Jln. Mr. Chr. Soplanit Poka-Ambon Telp. (0911) 379859, email: inseijurnal@gmail.com.

\section{Pedoman Penulisan Naskah}

a. Judul tidak lebih dari 15 kata dalam bahasa Indonesia dan bahasa Inggris.

b. Nama lengkap penulis tanpa gelar, penulis korespondensi disertai dengan alamat email.

c. Nama lembaga/institusi disertai alamat lengkap dengan kode pos.

d. Abstrak dalam bahasa Indonesia dan bahasa Inggris tidak lebih dari 200 kata.

e. Kata kunci dalam bahasa Inggris dan Indonesia maksimal 5 kata kunci ditulis dibawah abstrak

f. Pendahuluan, memuat latar belakang, perumusan masalah, keragka teoritis dan tujuan penelitian yang dibuat secara ringkas.

g. Metodologi, memuat lokasi dan waktu penelitian, bagaimana data diperoleh dan sumbernya, bagaimana metode analisis data, jika metode yang digunakan telah diketahui sebelumnya harus dicantumkan acuannya.

h. Hasil dan Pembahasan, memuat suatu topik atau permasalahan yang terkait dengan judul, didukung dengan tabel dan gambar yang dibahas secara komperhensif, dikomplementasikan dengan referensi primer yang mendukung, update dan advance.

i. Kesimpulan dan Saran, memuat pokok-pokok bahasan serta kemampuan mengartikulasi temuan pokok untuk saran yang diberikan.

j. Ucapan terima kasih (bila diperlukan).

k. Daftar Pustaka, dicantumkan dalam naskah bila ada pengutipan dari sumber lain. Proporsi daftar pustaka yang diacu yaitu $80 \%$ merupakan rujukan primer dan $80 \%$ merupakan terbitan 10 tahun terakhir. Disusun berdasarkan abjad, dan penulisan sesuai dengan peraturan yang sudah baku, misalnya:

[KKP] Kementerian Kelautan dan Perikanan. 2012. Statistik Perikanan Tangkap 2011. Direktorat Jenderal Perikanan Tangkap Kementerian Kelautan dan Perikanan

Bataglia P, Romeo T, Consoli P, Scottie G, and Andoloro F. 2010. Characterization of The Artisanal Fishery and Its Socio-Economic aspect in The Central Menditerranean Sea (Aeolian Islands, Italy). Fisheries Research 102:87-9.

Pingkan W, Hamzens S, dan Sumardjo. 2007. Strategi Inovasi Sosial Pengembangan Mutu Sumberdaya Manusia Nelayan. Jurnal Penyuluhan Volume 3 Nomor 1.

Fauzi A. dan Anna S. 2005. Pemodelan Sumberdaya Perikanan dan Kelautan. Untuk Analisis Kebijakan. PT. Gramedia Pustaka Utama. Jakarta.

Wibawa T. J, Novianto D, dan Nugroho B. 2012. Sebaran Spasial Kelimpahan Ikan Cakalang (Katsuwonus Pelamis) Berdasarkan Analisis Data Satelit Oseanografi. Prosiding InSINas, 2930 Nopember 2012.

Muksin D. 2006. Optimalisasi Usaha Perikanan Cakalang (Katsuwonus pelamis) Di Kota Tidore Kepulauan Provinsi Maluku Utara. Tesis. Program Pascasarjana IPB. Bogor.

Syandri H. 2013. Nelayan Cerdas, Nelayan Mandiri. http://www.bunghatta.ac.id//diunduh pada 12 September 2013).

1. Tabel, diketik dalam bahasa Indonesia, diberi judul pada bagian atas tabel, diberi nomor urut (tidak dalam bentuk JPEG).

m. Gambar dan grafik, diketik dalam bahasa Indonesia, diberi judul singkat pada bagian gawah gambar dan diberi nomor urut. 
PROGRAM STUDI AGRIBISNIS PERIKANAN

FAKULTAS PERIKANAN DAN ILMU KELAUTAN

UNIVERSITAS PATTIMURA

Jln. Mr. Chr. Soplanit, Poka - Ambon, Maluku Telepon : (0911) 379859

E-mail : inseijurnal@gmail.com

Web : http://ojs.unpatti.ac.id./index.php/insei

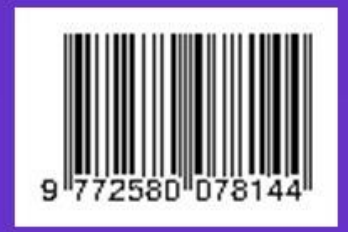

